\title{
PAISAGENS EM SOBREIMPRESSÃO: MARIA GABRIELA LLANSOL E A GEOGRAFIA DOS REBELDES
}

infanto-juvenil. Professora Titular em Estudos Literários da Faculdade de Letras da UFMG. Coordenadora no Brasil, da coleção das obras de Maria Gabriela Llansol,
publicadas pela Editora Autêntica, em 2011.

RESUMO: Este trabalho faz uma aproximação entre estes dois autores: Maria Gabriela Llansol e Jacques Lacan. Ta encontro se dá na proximidade das noções de "litoral" (Lacan) e "sobreimpressão" (Llansol) e na ressonância que elas provocam no campo dos estudos literários.

PALAVRAS-CHAVE: Maria Gabriela Llansol; Jacques Lacan, sobreimpressão; litoral

RÉSUMÉ : Ce travail fait une approche entre ces deux auteurs: Maria Gabriela Llansol et Jacques Lacan. Tel rencontre a lieu dans la proximité des notions de "littoral» (Lacan) et " surimpression " (Llansol) et dans les échos provoqués dans le champ des études litteraires.

MOTS-CLÉS : Maria Gabriela Llansol ; Jacques Lacan ; surimpression ; littotal 
Para Maria Inês de Almeida, desocidentada.

O que ela lia revelava um trabalho de calígrafo. Ao repassar a leitura, eu deparava com aquela caligrafia, aqueles arabescos em que as margens das folhas novas dos vegetais se enrolam para a págin superior. Tinham o mesmo sublinhado das folhas de oliveira e eu lancei-me, num transporte de alegria, para a sombra da minha árvore de fruto preferida que me falta a meu lado,

Maria Gabriela Llansol

Produzir a rasura definitiva, eis aí a façanha da caligrafia.

Jacques Lacan

\section{CENA 1: LITURATERRA}

Do alto do avião, ele vê a planície siberiana. O que ele vê, lá de cima, são traços que desenham nitidamente um litoral. E um litoral, ele observa, não é uma fronteira:

O litoral é o que coloca um domínio inteiro como fazendo a um outro, se assim o quiserem, uma fronteira. Mas justamente por não terem nada em comum, nem mesmo uma relação recíproca.

Lá do alto, ele reconhece, nesses traços que desenham um litoral, o domínio da letra, da escritura. "A escritura" - ele diz - " é esta sulcagem"2. E distingue: "A escritura não é a impressão"3.
Antes, um pensamento breve o acometera: "A civilização, lembrava naquela ocasião, para mim é o esgoto"4 ${ }^{2}$ E, mais tarde, quando retornava do Japão, em conexão com esse pensamento, ele concluiria: "Não há esperança para um ocidentado"s.

\section{CENA 2: O LITORAL DO MUNDO}

Duas décadas mais tarde, ela, que então se encontrava no "extremo ocidental do Brabante", propunha, com sua escrita, uma saída para os "ocidentados". Essa saída, ela a encontraria na técnica da "sobreimpresão":

Tudo se revelou no instante em que eu andava à procura do lugar, da geografia dessa linhagem,

e deparei com o denominado estético, o entresser entre o sensível e o racional, a imaginação criadora da mística árabe, que é, talvez, de todas as manifestações de sobreimpressão, a mais portentosa. Só a partir de tais confins, olhei para trás, para os reler e para os escrever a eles, figuras definitivamente incluídas no drama europeu. ${ }^{6}$

Já então ela havia escrito suas duas primeiras trilogias, sintomaticamente intituladas "Geografia dos Rebeldes" e "O Litoral do Mundo”. E, em 1991, nesse discurso proferido por ocasião da XI Bienal das Artes e da Cultura, na Bélgica, dedicada a Portugal (Europália), ela reiteraria que as figuras de sua obra possuem, em comum, "a técnica visual da sobreimpressão, a sua arte de ver o mundo sobreimpresso"
4. LACAN. "Lituraterra", p. 18

5. LACAN. "Lituraterra", p. 27.
6. LLANSOL. Lisboaleipsig 1: o encontro inesperado do diverso p, 131.

7. LLANSOL. Lisboaleipsig 1: o encontro inesperado do diverso, p, 129. 
8. LLANSOL. Lisboaleipsig 1: o encontro inesperado do diverso, p, 129

9. LLANSOL. Lisboaleipsig 1: o encontro inesperado do diverso, p, 126

10. LLANSOL. Lisboaleipsig 1: o encontro inesperado do diverso, $\mathrm{p}, 128$
Sobre essas figuras, ela diria ainda que "todos são rebeldes, a querer dobrar o tempo histórico dos homens, com o desejo intenso que eles se encaminhem para uma nova terra, bafejada por um céu novo".

É, portanto, nesse "litoral do mundo" - e lembremo-nos, com ele, de que um litoral distingue-se de uma fronteira justamente porque separa universos heterogêneos - que a "geografia dos rebeldes" pode ser traçada, trazendo, quem sabe, uma saída para o que ele teria chamado de "esgoto da civilização", o mundo ocidentado.

E, assim, nessa nova cartografia desenhada por paisagens sobreimpressas, quando seu "jogo de espelhos se estilhaçou", ela pôde vislumbrar uma nova direção:

O que eu procurava, sem o saber, era o logos, a que mais tarde chamei cena fulgor - o logos do lugar, da paisagem; da relação a fonte oculta da vibração e da alegria, em que uma cena - uma morada de imagens - dobrando o espaço e reunindo diversos tempos, procura manifestar-se ${ }^{10}$.

\section{CENA 3: CENA FULGOR}

E, então, lançados no centro de uma cena fulgor, ainda uma década mais tarde, em 2000, podemos ler, na abertura de um de seus livros, esta breve nota "biografemática"11.
Eu nasci em 1931, no decurso da leitura silenciosa de um poema. Só havia tecidos espalhados pelo chão da casa, as crenças ingênuas de minha mãe. Estavam igualmente presentes as páginas que os leitores haveriam de tocar (como a uma pauta de música), apenas com o instrumento da sua voz. Eu fui profundamente desejada, profundamente mal desejada e com amor.

- A voz está sozinha - disse minha mãe, ainda eu estava no seu ventre, a ler-me poesia.

- Não por muito tempo - responderam àquela que me iniciava na língua. E eu nasci na seqüência de um ritmo.

Eu nasci para acompanhar a voz, faze-la percorrer um caminho. De um lado a outro do percurso, não sei o que existe, o caminho caminha,

eu deslumbro-me quando o tempo se suspende,

e me permite parar a contemplar o espaço sem tempo. Como, de resto, é evidente, não tive intenção de conceber-me. Dei comigo deitada no quarto das sombras com uma perspectiva de descida aos infernos diante dos olhos. Ninguém estava à altura de receber-me, nenhuma relação era exacta para me tornar equilibrada, ou útil. No quarto das sombras a luz entrava a jorros por duas grandes janelas de sacada mas eu habitava aí, não ultrapassava o limiar do corredor que possuía uma passadeira de oleado negro e brilhante porque, diziam,
11. Refiro-me, aqui, à noção de biografema" proposta por Roland Barthes, que se articula perfeitamente à noçăo de "letra" tal como proposta por Lacan. A respeito do biografema, ver p. 13. 
12. LLANSOL. Onde vais, DramaPoesia?, p. 11-12.

13. LLANSOL. Onde vais, DramaPoesia?, p. 10

14. LLANSOL. Contos do mal errante, p. 89. havia um fantasma acocorado na entrada e que, afinal, nada mais era do que, a certas horas do dia, o volume rutilante do sol no oleado. Descobri que se, em vez de me concentrar na sombra do corredor, me deitasse de costas a olhar a mancha rutilante, o meu olhar poderia realizar o caminho inverso da luz e pousar no ramo mais alto da árvore e aprender com esta a produzir clorofila - a primeira matéria do poema. ${ }^{12}$

Assim se apresenta ao legente aquela que, já de início, havia anunciado: "Legente, o mundo está prometido ao DramaPoesia"13. Do litoral do mundo, ela anuncia: "o mundo está prometido ao Drama-Poesia”. Como um deslocamento do drama europeu, nascente de suas figuras, ela nos promete o drama-poesia.

Desse drama, sabemos tão somente que ele tem origem na clorofila - "primeira matéria do poema". E que, portanto, caminhar a seu encontro significa "crescer em direção à árvore" e não em direção ao estreito corredor, ao quarto das sombras. Ou, conforme já escrevia a autora, em Contos do mal errante, livro de 1986: "não desejava desenvolver-me em termos de países, mas de árvores com afinidades". ${ }^{14}$

\section{CENA 4: NUVENS}

No mesmo ano de 1991, em outro discurso, por ocasião do prêmio da crítica de 1990 a um de seus livros, ela observari que a língua portuguesa, irremediavelmente presa ao "lirismo melancólico", ao "realismo da queda", exploraria, com mais ênfase, apenas um dos sentidos da palavra "pena" e, esquecendo-se da leveza do pássaro, preferiria cair das nuvens. ${ }^{15}$

Ao ouvir essas palavras proferidas por ela, em um discurso, quase que também o ouvimos: "não há esperança para um ocidentado". Ele, que justamente sobrevoava as nuvens quando vislumbrou, lá do alto, o litoral do mundo, percebeu também que, aonde as nuvens escorrem, uma rasura se produz, lá embaixo, na areia. A essa rasura - sulcagem - ele chamou: lituraterra, essa escritura de letras sobre a terra.

E ela, como a chamaria? Sobreimpressão, a produzir textualidade, em contraposição à narratividade. E, em seguida, indagaria: "Mas o que pode nos dar a textualidade que a narratividade já não nos dá (e, a bem dizer, nunca nos deu)?"16 E ela mesma propõe uma resposta, que é também uma saída para o drama europeu:

A textualidade pode dar-nos acesso ao dom poético [...] O dom poético é, para mim, a imaginação criadora própria do corpo de afectos, agindo sobre o território das forças virtuais, a que poderíamos chamar os existentes-não-reais ${ }^{17}$.

\section{CENA 5: EM PAISAGEM ESTRANHA}

Tanto Maria Gabriela Llansol quanto Jacques Lacan encontravam-se "em paisagem estranha"18, quando pensaram a
15. LLANSOL. Lisboaleipzig 1: o encontro inesperado do diverso, p. 113-115.

6. LLANSOL. Lisboaleipzig 1: o encontro inesperado do diverso, p. 120.

17. LLANSOL. Lisboaleipzig 1: o encontro inesperado do diverso, p. 120.

18. Faço aqui referência a um outro discurso de Llansol, em Lisboaleipsig 1: o encontro inesperado do diverso, p. 86-87 Em paisagem estranha.
EM TESE v. 19

SET.-DEZ. 2013 
19. LLANSOL. Lisboaleipzig 1: o p.

20. LACAN. “Lituraterra", p. 28

21. A esse respeito, ver BARTHES. Aula.

22. A esse respeito, ver ALMEIDA. Desocidentada.

23. Lembro, aqui, o trecho "A boa nova anunciada à natureza", no livro Onde vais, Drama à " "N em que Llansol escreve, a p. 45: "Na paisagem, ou na geografia imaterial da especce distribum om vaun formum poms". que "há uma grande finidu que ligá uma grande afinidade que

24. LLANSOL. Contos do mal errante p. 231, 232. sobreimpressão e a escritura, em sua relação com o real. Ela, no extremo ocidental do Brabante, formula que "o real é um nó que se desata no ponto rigoroso em que uma cena fulgor se enrola, e se levanta" ${ }^{\prime 1}$. Ele, sobrevoando a planície siberiana ao retornar do Japão, descobre que a escritura, como "o que chove do semblante", "está no real"20.

E, se entendermos com Barthes que a literatura é o "fulgor do real”21 e não exatamente sua representação - já que o real é justamente o irrepresentável -, entenderemos, com Llansol e Lacan, que a escritura não é da ordem da impressão, mas da sulcagem: sobreimpressão.

E aí, a partir desse lugar em que uma dobra se efetua "dobrando o espaço e reunindo diversos tempos" -, é preciso admitir que essa técnica que nasce na paisagem da Bélgica, em sobreimpressão com a paisagem de Portugal, não se restringe a representar o drama europeu, mas abre-se, afinal, ao drama-poesia, que só o dom poético é capaz de escrever.

Estar no drama-poesia é viver, na reunião de diversos tempos, a promessa de um outro mundo. Um mundo de poeta e de vagabundos, capazes de "desocidentar" 22 os formadores e os construtores ${ }^{23}$ e de apontar, em seu litoral, ao fim da nossa viagem, para o "rosto claro e radioso da alegria ${ }^{24}$.

Essa viagem que atravessa o simbólico - as grandes paisagens míticas do drama europeu - em direção ao real - as paisagens sobreimpressas do drama-poesia -, ele poderia realizá-la em linha reta, pela via da escritura. E diria: "Não há reta senão escritura" 25 . E também ela que, ao entender a textualidade como uma reta a unir diversos tempos e diversos espaços, proporia: "o texto é a mais curta distância entre dois pontos"26.

Deixemo-los estarem assim, sobreimpressos, Llansol e Lacan. E estendamos, entre os dois, "as paragens onde não há raízes", o "deserto do nome do homem" e "um ponto de vista não- humano sobre o deserto" ${ }^{27}$. Só assim, talvez, possa haver alguma esperança para nós, ocidentados, que enfim ultrapassaremos o drama europeu em direção ao drama- poesia. E eis-nos, afinal, diante do litoral do mundo onde, conforme escreveu Rimbaud, poeta em linha reta da linhagem de Llansol, o mar "estrada com o sol". ${ }^{28}$

\section{REFERÊNCIAS}

ALMEIDA, Maria Inês de. Desocidentada. Belo Horizonte: FALE/ Editora UFMG, 2008.

BARTHES, Rodand. Sade, Fourier, Loyola. Lisboa: Relógio D’Água, 1979

BARTHES, Roland. Aula. SP: Cultrix, [s.d.].

BATAILLE, George. L’Érotisme. Paris: Minuit, 1957.
25. LACAN. “Lituraterra”, p. 20

26. LLANSOL. Um falcão no punho, p. 135.

27. LLANSOL. Lisboaleipzig 1: o encontro inesperado do diverso, p. $124 ; 129$

28. Refiro-me, aqui, ao verso de Rimbaud, citado por George Bataille na introdução de 'Érotisme, p. 32. Segundo Bataille, a poesia, tanto $o$ quanto o erotismo, é capaz de nos conduzir à ultrapassagem de um certo limite, o limite da descontinuidade, ao nos conduz "à indistinção, à confusão dos objetos distintos". Nas palavras de Rimbaud, citadas por Bataille, a poesia é a eternidade: "c'est la mer allée avec le soleil". 
LACAN, Jaques. Lituraterra. Che Vuoi, Porto Alegre, Cooperativa

Cultural Jacques Lacan, v. 1, n. 1, 1986

LLANSOL, Maria Gabriela. Contos do mal errante. Lisboa: Rolim, 1986

LLANSOL, Maria Gabriela. Lisboaleipsig 1: o encontro

inesperado do diverso. Lisboa: Rolim, 1994.

LLANSOL, Maria Gabriela. Onde vais, Drama-Poesia? Lisboa:

Relógio D’Água, 2000.

LLANSOL, Maria Gabriela. Um falcão no punho. 2 ed. Lisboa: Relógio D'Água, 1998. 